\title{
IDENTIFYING COMMUNICATION APPREHENSION LEVELS IN SENIOR-LEVEL INFORMATION SYSTEMS MAJORS: A PILOT STUDY
}

\author{
Dacia Charlesworth, Robert Morris University, charlesworth@rmu.edu
}

\begin{abstract}
Given the importance of communication skills in the classroom and workplace, it is surprising that no extant research focuses explicitly on senior-level information systems (IS) majors and their levels of communication apprehension (CA). To fill that void, this study examines the levels of CA among seniorlevel IS majors. Participants $(n=51)$ enrolled in an IS senior capstone course completed the Personal Report of Communication Apprehension (PRCA) measure. IS majors' PRCA scores were then compared to national norms. Unexpectedly, no statistically significant differences were observed between the scores of the IS majors and the national norms; however, IS majors do experience moderately high levels of $C A$ and the most anxiety-inducing setting was speaking in public, whereas the least anxiety-inducing setting was speaking one-on-one.
\end{abstract}

Keywords: Communication Skills, Student Attitudes, Capstone IS Course, Information Systems Curricular Design

\section{INTRODUCTION}

Faculty and employers have long acknowledged the importance of communication skills in the curriculum and workplace. Moreover, an individual's level of success in the classroom and workplace is greatly influenced by one's ability to communicate. While employers readily acknowledge the importance of all types of communication skills (e.g., writing and listening), they consistently point to oral communication and presentation skills as the most important indicators for career success [8]. Research demonstrates that although students recognize the importance of being able to communicate well and believe that communication skills should be integrated into the curriculum much more [9], they have an aversion to communicating orally, particularly before a group of strangers [14]. Unfortunately for students who dislike communicating orally, studies have found that oral communication, while being students' greatest weakness, is the most important communication skill to possess [3].
Most students experience some sort of communication apprehension (CA) when speaking to a large group, in meetings, or in dyads. For some, CA is manageable; however, it severely limits others' performance in numerous ways. CA has the ability to negatively affect student performance within the classroom [6, 17], may ultimately affect the ways in which individuals conduct themselves during job interviews [2, 4], and subsequently affect job performance $[1,5]$. Given the impact CA can have on student success-in the college classroom and beyond-it is vital to determine students' levels of $\mathrm{CA}$ so that we can assist them in becoming more competent communicators.

As a construct, CA has been heavily studied in the field of communication studies and has proven to greatly influence one's ability to interact with others in public, small group, and dyadic contexts. In the field of information systems (IS), however, the CA levels of IS majors have yet to be explored in isolation. The research that has been conducted on CA and IS majors focuses on computer anxiety [17] along with on-line learning environments [16]. That is, research has not yet been published that compares and contrasts IS majors' level of CA to national norms. Additionally, extant research on CA and IS students has yielded results from participants only in introductory courses thus participants in these studies may not have even been IS majors.

The purpose of this study, then, is to determine the degree to which senior-level IS majors experience CA. As this study is the first of its kind, the primary objectives of this project are to determine the levels of CA in senior-level IS majors and then compare those levels to the national norms of CA. Ascertaining this information will allow faculty to know how IS majors compare to others as well as indicate the extent to which faculty need to incorporate oral communication projects into their curricula to better assist students in becoming more competent communicators. This paper is organized as follows. First, a theoretical overview of CA is offered and the hypothesis is presented. Next, the methodology of the current study is discussed. Third, the results of the study are presented. Finally, the significance of this research is discussed and directions for future research are offered. 


\section{THEORETICAL OVERVIEW}

\section{CA as a Construct}

The study of an individual's fear of interacting with others has been researched using terminology such as social fear, reticence, communication apprehension, unwillingness to communicate, audience anxiety, stage fright, and social anxiety. For the purposes of this study, McCroskey's definition of CA will be used because of its inclusiveness: "an individual's level of fear or anxiety associated with either real or anticipated communication with another person or persons" [12, p. 78]. CA is usually thought of as either a trait-like or state-like behavior. Trait-like CA is "characterized by fear or anxiety in all types of oral interaction, from talking to any individual person to talking to others in a small group to talking to a large number of people" [11, p. 281]. State-like CA is described as "a normal anxiety response that most people experience when confronted with oral communication in some sort of public setting" [11, p. 281]. It is important to note that CA is usually measured on a continuum (low to high) and often changes for each person based on individual situations (e.g., a student may experience high levels of CA when speaking to someone one-on-one; however, that same student may experience low levels of CA when interacting in a small group). Thus, a person with trait-like CA would always experience a high level of apprehension-no matter what the oral communication context whereas a person with state-like CA would have CA levels that fluctuate in different settings.

McCroskey notes that people who experience high levels of CA will avoid and/or withdraw from oral interaction with others; as a result of that avoidance/withdrawal, they will be seen in a poor light by themselves and others; and this poor image results in economic, political, and academic consequences [12, p. 82]. Focusing on McCroskey's claim, researchers have investigated the link between source credibility and the impact of CA. Researchers found that supervisors with high levels of perceived CA were viewed as having less source credibility, overall affect, and likeability [11]; and that students with high levels of CA tend to speak less frequently and for shorter durations than do their less apprehensive peers $[10,11]$. Not surprisingly, individuals who experience high levels of $\mathrm{CA}$ were found to offer more negative and fewer positive selfstatements [7] and, when they did communicate, were less comprehensible [6]. Thus, research on CA supports McCroskey's claims that individuals with high levels of CA stand to suffer economic, political, and academic consequences.

\section{Scope of CA Research}

Obviously, most of the research relating to CA has been conducted within the field of communication studies; however, other disciplines have begun focusing on the importance of identifying student levels of CA. In the area of IS, two studies focus on $\mathrm{CA}$ in addition to other variables. Vician and Brown [16] examined the impact of $\mathrm{CA}$ in an on-line learning environment. They found that educators need to include various participation opportunities for an on-line learning environment and that one's level of CA can negatively impact one's learning experience. In another study, Vician and Davis [17] link communication apprehension to computer anxiety to examine both variables' impact students in an introductory computing course.

While the two studies conducted in the field of IS yield interesting results, both projects used participants enrolled in introductory courses who may or may not have been IS majors. To better evaluate the levels of CA for IS majors, this study assesses the CA levels of students enrolled in a departmental capstone course. By analyzing the CA levels of senior IS majors, rather than analyzing students in various majors enrolled in an introductory level course, students' future performance in the workplace can be better assessed.

\section{Hypothesis}

As noted above, no empirical studies examining IS senior-level CA levels in isolation exist. Upon review of the theoretical discussion of $\mathrm{CA}$ and the prior findings of student levels of CA related to course content and delivery, the following five-part hypothesis is tested:

$\boldsymbol{H}$ : Senior-level information systems majors will have (a) an increased rate of CA overall compared to national norms, (b) an increased rate of CA in the group setting compared to national norms, (c) an increased rate of $\mathrm{CA}$ in the meeting setting compared to national norms, (d) an increased rate of CA in the public speaking setting compared to national norms, and (e) an increased rate of CA in the dyad setting compared to national norms. 


\section{METHODOLOGY}

\section{Participants, Course, and Procedures}

Participants included 51 students enrolled in a small, private Mid-Atlantic university completing a threecredit, upper level computing course offered by the Department of Computer and Information Systems. Students received no credit for participating in the study; however, course time was allocated so that students could complete the questionnaire. All participants had previously completed a public speaking course.

The purpose of this course is to provide students with an integrated theoretical and practical perspective of technology and information systems as process and functional components of an organization. The course emphasizes refining individual communication skills necessary to the field of IS. The student completes journal assignments and case studies, practices team problem solving, participates in structured group discussions, conducts research, writes reports, and delivers oral presentations. Students must have completed 96 hours in order to enroll in the course.

\section{Measure}

The variable of interest for this study is the selfreported student levels of CA. To determine participants' levels of CA, the Personal Report of Communication Apprehension (PRCA) was administered. The PRCA is a 24-item, Likert-type self-report instrument that has produced reliable and valid multigenerational data [15]. The PRCA assesses respondents' feelings about oral communication across a broad range of interactions: public speaking, small groups, meetings, and dyads (one-on-one). The reliability of this survey instrument exceeds 0.90, which offers evidence of predictive reliability.
After participants' completed the questionnaire, the results were categorized into five contexts: Overall levels of CA and levels of CA when speaking in groups, meetings, public, and dyads. These levels were then compared to the nationally-normed PRCA levels. The national norms for the PRCA used in this study are derived from McCroskey et al. [13] and have been established using large samples of college/university students and adult non-students.

\section{RESULTS}

All participants were seniors. Gender distribution was $73 \%$ male and $27 \%$ female. All students had previously completed a three-credit Public Speaking course as part of the general education curriculum. Additionally, majors are required to complete four upper-division courses that are designated as "communication intensive." In these communication intensive courses students are expected to deliver several oral presentations and complete several written projects. The course used in the current study is designated as a communication intensive course.

\section{Communication Apprehension Levels of Information Systems Majors}

To test the hypothesis, participants' responses to the PRCA were calculated to determine their levels of CA in five different settings. Those levels were then subjected to a regression analysis. Table 1 presents the descriptive statistics for this study. Participants' had a moderately high level of CA overall and reported a high level of CA when speaking in public. The comparison between the PRCA scores of IS majors and the national norms are presented in Table 2. Table 2 shows that there is no statistically significant difference between the IS majors' levels of CA and the national norms; thus, no parts of the hypothesis are supported.

Table 1. Descriptive Statistics for IS Majors

\begin{tabular}{llll} 
Communication Setting & Mean & SD & SE \\
\hline Overall & $73.16^{*}$ & 4.97 & 0.67 \\
Group & 17.10 & 1.63 & 0.23 \\
Meeting & 17.88 & 1.9 & 0.27 \\
Public Speaking & $18.14^{* *}$ & 2.22 & 0.31 \\
Dyad & 11.06 & 1.57 & 0.22
\end{tabular}

*Scores between 55-83 indicate moderate levels of CA

**S Scores over 18 indicate the presence of CA 
Table 2. PRCA Levels of IS Majors and National Norms

\begin{tabular}{lllll} 
& IS Majors' Mean & SD & National Norm Mean & SD \\
\hline Overall & $73.16^{*}$ & 4.97 & $65.6^{*}$ & 15.3 \\
Group & 17.10 & 1.63 & 15.4 & 4.8 \\
Meetings & 17.88 & 1.9 & 16.4 & 4.8 \\
Public Speaking & $18.14^{* *}$ & 2.22 & $19.3^{* *}$ & 5.1 \\
Dyad & 11.06 & 1.57 & 14.5 & 4.2
\end{tabular}

*Scores between 55-83 indicate moderate levels of CA

**Scores over 18 indicate the presence of CA

\section{DISCUSSION}

The results of the PRCA indicate that while IS majors do experience moderately high levels of CA overall, in groups, in meetings, and in public those levels are not statistically significantly higher compared to national norms. Although the IS majors' overall CA levels were not statistically different, McCroskey et al. [13] report that the distribution for the national sample is $16.7 \%$ for high levels of CA, $66.6 \%$ for moderate levels, and $16.7 \%$ for low levels. The distribution for IS majors, however, was $98 \%$ for the moderate level and $2 \%$ for the high level with $45 \%$ of participants scoring between 71-74. This indicates that the overall CA level in this sample is consistently moderately high.

Some reasons for the nullification of the hypothesis may be maturation and previous experience. Since participants were seniors enrolled in a capstone project, it could be argued that their CA levels would be naturally reduced while completing their degree program. Participants' had also completed an introductory public speaking course and three other communication-intensive courses; thus, they had extensive experience developing and delivering oral presentations which may account for their lowered CA levels in this area compared to the national norms. It is also interesting to note the low levels of CA in the dyad setting. Although a comparison of the dyad CA levels between IS majors and the national norms did not yield statistically significant results, the IS majors' mean is much lower in this setting. This is an interesting finding given the stereotypical view of IS majors as loners and as those who wish to avoid contact with others.

In sum, the data suggest that IS majors do experience a moderate amount of CA overall and that the setting that produces the most anxiety is public speaking while the setting that produces the least amount of anxiety is dyadic. Implications for practice and future research are presented next.

\section{CONCLUSION}

The primary objectives of this study were to determine the CA levels of senior IS majors and then compare those levels to the national norms. IS majors were found to have moderately high levels of CA overall, but the levels were not statistically different when compared to national norms. IS majors reported feeling apprehensive when speaking in public, some apprehension when speaking in meetings and to groups, but no apprehension when communicating one-on-one.

The results of this study suggest three primary implications for teaching IS majors. First, participants reported a moderate level of apprehension overall; thus, faculty need to continue integrating oral communication activities (involving both public speaking and group activities) into their classrooms so that students can become more comfortable when interacting in these contexts and, ostensibly, lower their levels of CA. Second, students' levels of CA in the dyad setting indicated that students felt very comfortable communicating one-on-one. As educators, we need to keep students' comfort level in this setting in mind when developing assignments. That is, faculty could develop multiphase assignments that begin with students interacting with only one other person and then have students progressively interact with a larger group. Presumably, this type of systematic desensitization would increase student comfort levels and would thereby decrease CA levels. Finally, it is significant to note that even though students had previously completed a public speaking course, they still reported the highest level of CA in this setting. This finding reminds faculty that in order to help reduce CA levels and to increase presentation skills, students 
need to have multiple opportunities to develop and deliver presentations in all classes.

Three primary implications for future research arise from this study. First, this study should be replicated using a larger sample size. Now that data exist that demonstrate senior IS majors do experience CA, more research needs to be conducted to determine if other student responses remain as consistent as this sample. Second, it would be interesting to assess the impact of IS curricula on CA. Therefore, this study could be replicated comparing the CA levels of firstyear IS students to graduating majors. Another option would be to conduct a longitudinal study where IS majors complete the PRCA at the end of each academic year. This type of information would allow faculty to chart students' CA levels as they progress through the major. Finally, it would be revealing to couple CA levels with performance based indicators (e.g., compare student-reported CA levels to instructor's grades on a specific presentation) to compare student and faculty perception of IS majors' communication skills.

As communication skills continue to impact one's ability to advance in the workplace and succeed in the classroom, it is vital to understand how we can assist our students in becoming better communicators. Identifying and reducing student CA levels are two measures to ensure that our students are, at the very least, more comfortable in communication situations.

\section{REFERENCES}

1. Addams, H. L. (1981). Should the big eight teach communication skills? Management Accounting, May, 37-40.

2. Ayres, J., Hopf, T., \& Will, A. (2000). Are reductions in $\mathrm{CA}$ an experimental artifact? A Solomon four-group answer. Communication Quarterly, 48, 19-26.

3. Burk, J. (2001). Communication apprehension among Master's of Business Administration students: Investigating a gap in communication education. Communication Education, 51, 51-58.

4. Daly, J. A., Richmond, V. P., \& Leth, S. (1979). Social communicative anxiety and the personnel selection process: Testing the similarity effect in selection decisions. Human Communication Research, 6, 18-32.

5. Dirks, R., \& Buzzard, J. (1997). What CEOs expect of employees hired for international work, Business Education Forum, 51, 3-7.
6. Freimuth, V. S. (1976). The effects of communication apprehension on communication effectiveness. Human Communication Research, Spring, 289-298.

7. Glass, C. R., Merluzzi, T. V., Biever, J. L., \& Larson, K. H. (1982). Cognitive assessment of social anxiety: Development and validation of a self-statement questionnaire. Cognitive Therapy and Research, 6, 35-55.

8. Hynes, G. E., \& Bhatia, V. (1996). Graduate business students' preferences for the managerial communication course curriculum. Business Communication Quarterly, 59, 45-55.

9. James, M. L. (1992). Are we teaching what employers want? Business Education Forum, 46, 8-10.

10. Jordan, W. J., \& Powers, W. G. (1978). Verbal behavior as a function of apprehension and social context. Human Communication Research, 4, 294-300.

11. Lederman, L. C. (1982). Suffering in silence: The effects of fear of talking on small group participation. Group \& Organizational Studies, 7, 279-294.

12. McCroskey, J. C. (1977). Oral communication apprehension: A summary of recent theory and research. Human Communication Research, 4, 78-96.

13. McCroskey, J. C., et al. (1992). Communication apprehension and self-perceived communication competence of at-risk students. Communication Education, 41, 349-357.

14. Merrier, P., \& Dirks, R. (1997). Student attitudes towards written, oral and e-mail communication. Business Communication Quarterly, 60, 89-99.

15. Sawyer, C. R., \& Behnke, R. R. (2002). Behavioral inhibition and the communication of public speaking state anxiety. Western Journal of Communication, 66, 412-423.

16. Vician, C., \& Brown, S. A. (2001). Reengineering participation through on-line learning environments: An examination of communication apprehension, choice, and performance. Journal of Computer Information Systems, 42, 26-36.

17. Vician, C., \& Davis, L. R. (2002/2003). Investigating computer anxiety and communication apprehension as performance antecedents in a computing-intensive learning environment. Journal of Computer Information Systems, 43, 51-56. 